\title{
Modelling the Efficacy of Neprilysin from Various Species in Degrading Different Amyloid- $\beta$ peptides: Potential Application in Development of Therapeutics for Alzheimer's Disease
}

\author{
Arun HS Kumar
}

\begin{abstract}
Recombinant neprilysin due to its degradation potential against Amyloid- $\beta(A \beta)$ peptides has been looked at as a potential therapeutic candidate for treating Alzheimer's disease (AD). However the enzymatic activity of neprilysin against different $A \beta$ peptides can variable which significantly limits the therapeutic optimization. Using the molecular interaction analysis and modelling it against the known enzyme-substrate kinetics, this study developed a novel approach to predicting biosimilar enzyme-substrate kinetics. The known enzyme-substrate kinetics of human recombinant neprilysin with $A \beta_{1-40}$ peptide was used as the prototype to assess the affinity and efficacy of various inter and intra-species neprilysin- A $\beta$ peptide enzyme kinetics based on the relative molecular interaction analysis. Significant inter and intra-species variations in neprilysin- $A \beta$ peptide enzyme kinetics was observed which further validated the need for optimizing enzyme kinetics tailored to specific substrate degradation. The novel enzyme kinetics modelling approach described in this study can be helpful in the developing of recombinant enzymes/peptides for personalised therapeutic applications.
\end{abstract}

Key words: Neprilysin, Amyloid- $\beta$ peptides, Receptor pharmacology, Enzyme kinetics, Alzheimer's disease.

\section{INTRODUCTION}

Neprilysin is a peptidase which is reported to cleave Amyloid- $\beta(A \beta)$ peptides associated with Alzheimer's disease (AD). ${ }^{1-3} \mathrm{~A} \beta$ peptides are major constituents of amyloid plaques which correlate with progression of $\mathrm{AD}$ in humans. ${ }^{1-3}$ Despite the well-known role of $\mathrm{A} \beta$ peptides in $\mathrm{AD}$, the rodent models of $\mathrm{AD}$, which have been the predominant tools for discovery of $\mathrm{AD}$ therapeutics don't show considerable presence of amyloid plaques or the related neurofibrillary tangles. ${ }^{4,5}$ This discrepancy has been attributed to species specific differences in the amino acid sequences of $\mathrm{A} \beta$ peptides which consequently influence enzymatic activity of neprilysin against $A \beta$ peptides, ${ }^{1,4}$ Further recent studies have suggested that neprilysin can degrade murine $A \beta$ with a much higher efficiency than the human $A \beta,{ }^{1}$ which may partly explain the reasons for failure to observe amyloid plaques in the rodent models of $\mathrm{AD}$. The $\mathrm{A} \beta$ are produced as a consequence to degradation of amyloid precursor protein (potentially by neprilysin).$^{3,6-8}$ Several soluble forms of $A \beta$ are produced which may have a variable enzyme-substrate kinetics with the neprilysin., ${ }^{3,6-8}$ Likewise six potential isoforms of neprilysin are also reported of which only two isoforms have been cloned and are reported to have high degree of homology.

Cite this article : Kumar AHS. Modelling the Efficacy of Neprilysin from Various Species in Degrading Different Amyloid- $\beta$ peptides: Potential Application in Development of Therapeutics for Alzheimer's Disease . BEMS Reports. 2021;7(2):25-8.
Considering the efficiency of neprilysin to cleave $\mathrm{A} \beta$ peptides, there may be merit in administering stabilised forms of neprilysin as a therapeutics for AD. ${ }^{9,10}$ However development of neprilysin to deliver it to its site of action in the brain and achieve required therapeutic efficacy comes with several challenges. One such challenge is the effectiveness with which various forms of $A \beta$ can be cleaved to facilitate their optimal removal from the brain. The cleaving of $A \beta$ peptides to achieve an optimal physiological balance is essential as neprilysin knockout mice are reported to have better cognitive potential with aging, ${ }^{1}$ suggesting neither neprilysin inhibitors nor its activator in exclusivity can be therapeutically beneficial in AD. Under these circumstances controlled delivery of recombinant neprilysin for optimal regulation of $A \beta$ peptides in the brain will be therapeutically beneficial in $\mathrm{AD}$. Developing recombinant neprilysin for therapeutic use will require a detailed understanding of the enzyme kinetics between neprilysin and $A \beta$ peptides. Hence this study modelled the enzyme kinetics between different forms neprilysin and $A \beta$ peptides, which can be helpful in optimization of recombinant neprilysin for therapeutic development.

\section{Arun HS Kumar}

Stemcology, School of Veterinary Medicine, University College Dublin, Belfield, Dublin, IRELAND.

\section{Correspondence}

Dr. Arun HS Kumar, DVM, PhD.

School of Veterinary Medicine, University College Dublin, Belfield, Dublin-04, IRELAND.

Phone no: 0035317166230

E-mail: arun.kumar@ucd.ie

History

- Submission Date: 04-05-2021;

- Review completed: 22-05-2021

- Accepted Date: 28-05-2021.

DOI : 10.5530/bems.7.2.9

Article Available online

http://www.bemsreports.org

Copyright

(c) 2021 Phcog.Net. This is an openaccess article distributed under the terms of the Creative Commons Attribution 4.0 International license. 


\section{MATERIALS AND METHODS}

\section{Protein structure}

The protein data bank (PDB; https://www.rcsb.org/) was searched with Neprilysin and Amyloid $\beta$ peptides as key words to identify the reported 3D structures. There were five Neprilysin and multiple Amyloid $\beta$ peptide 3D structures identified in the PDB database. Of the five Neprilysin structures, two each were of human and bacterial origin, while one was from rabbits. The following neprilysin and Amyloid $\beta$ peptides (PDB ID given) were used: 5JMY (Human Neprilysin from Spodoptera frugiperda expression system, 6GID (Human Neprilysin from Komagataella pastoris expression system), 4XBH (Soluble rabbit neprilysin), 6GHX (Bacterial Thermolysin; Geobacillus stearothermophilus), 1THL (Bacterial Thermolysin; Bacillus thermoproteolyticus), 4XFO (Amyloid-forming segment TAVVTN from human Transthyretin), 5TPT (Amyloid Precursor-Like Protein 2 (APLP2) E2 Domain;Human), 3SGP (Amyloid segment of alphaBcrystallin residues 90-100;Human), 2ROZ (Cytoplasmic tail of amyloid precursor protein;Mouse), 2YT1 (Cytoplasmic tail of amyloid precursor protein; Mouse), 4YN0 (Crystal structure of amyloid precursor protein E2 domain; Mouse), 2KJ7 (Rat Islet Amyloid Polypeptide), 1NMJ (Rat Amyloid beta-1-28), 4DBB (Amyloid precursor protein;Rat), 2BFI (Synthetic amyloid fibril), 2ONX (Amyloid cross-beta spines;Yeast)

Additionally the reported sequence of human Amyloid $\beta 1-40$ was used to construct the 3D structure using the Chimera software. ${ }^{11-13}$

\section{Molecular docking of the 3D structure}

The 3D structure of $\mathrm{A} \beta$ peptides were individually docked against the five neprilysin structures (5JMY, 6GID, 4XBH, 6GHX and 1THL) to identify the number of interaction sites through formation of hydrogen bonds using the Chimera software. ${ }^{11-13}$ The number of interaction sites observed between the 5JMY and Amyloid $\beta 1-40$ was taken as the baseline for all further estimations.

\section{Enzyme kinetics modelling}

The enzyme kinetics of 5JMY and Amyloid $\beta 1-40$ interactions are extensively reported in the literature and forms the basis of several commercially available kits to assess neprilysin activity. ${ }^{1,6,8,14-16}$ Hence the enzymatic cleaving of Amyloid $\beta 1-40$ (at a substrate concentration of $0.625,1.25,2.5,5,10,15$ and $20 \mu \mathrm{M}$ ) was studied in presence of $5 \mathrm{nM}$ concentration of recombinant neprilysin (5JMY). The resultant enzymesubstrate kinetic curve was used for modelling the kinetics of rest of the Amyloid $\beta$ (4XFO, 5TPT, 3SGP, 2ROZ, 2YT1, 4YN0, 2KJ7, 1NMJ, 4DBB, 2BFI, 2ONX, A $\beta 1-40$ ) and neprilysin (5JMY, 6GID, 4XBH and 6GHX) combinations. For the modelling of the enzyme-substrate kinetic curve, both a $3^{\text {rd }}$ and $4^{\text {th }}$ degree polynomial equation was used as these curves had high coefficient of determination i.e., $r^{2}=0.97$ and 0.99 respectively, thus allowing better predictive power. In similar lines the enzyme kinetics was also modelled with fixed Amyloid $\beta 1-40(15 \mu \mathrm{M})$ concentration and varying neprilysin $(0.625,1.25,2.5,5,10,15$ and $20 \mathrm{ng})$ concentration. However in this case a second degree polynomial curve was used as this had a high coefficient of determination $\left(r^{2}=0.99\right)$. From the enzyme kinetic curves, a Lineweaver-Burk plot was made for each of the neprilysin and Amyloid $\beta$ combinations to estimate the Vmax and $\mathrm{Km}$ values. Further to get an overview of the spread of Vmax and $\mathrm{Km}$ values for all the neprilysin and Amyloid $\beta$ combinations, an innovative approach of plotting $\mathrm{Km}$ against the LogVmax was adopted in this study.

\section{RESULTS}

The number of molecular interactions between different neprilysin and Amyloid $\beta$ combinations was highly variable (Table 1 ). There were 48 hydrogen bonds observed between 5JMY and Amyloid $\beta 1-40$ interactions. As this enzyme-substrate combination is widely studied in the literature, the number of hydrogen bond interactions in this combination was considered as baseline and formed the basis for modelling the enzyme-substrate kinetics of rest of the neprilysin and Amyloid $\beta$ combinations. Accordingly the Michaelis-Menten kinetics of neprilysin (5JMY) and Amyloid $\beta 1-40$ as a baseline was modelled to generate the enzyme saturation kinetics of rest of the combination based on the ratio differences (Hydrogen bond factor) in their respective hydrogen bonds shown in Table 1. The Hydrogen bond factor was multiplied with the baseline curve generated either at constant neprilysin (Figure 1) or at constant Amyloid $\beta$ (Figure 2) concentration. The considerable variations in the enzymatic activity of the different neprilysin and Amyloid $\beta$ combination is evident from these graphs (Figure 1 and 2). All the four neprilysin evaluated in this study had greater affinity and efficacy towards the mouse $A \beta$ peptides compared to human, rat, synthetic or yeast derived $A \beta$. The least enzymatic activity of neprilysin was observed against the yeast and synthetic $\mathrm{A} \beta$.

Despite the considerable variations in the enzyme kinetics curves of various neprilysin and $A \beta$, the Km value of this reaction was consistently around $2.3 \pm 0.4 \mu \mathrm{M}$ (Figure 3 ). The outlier values were mostly observed for $\mathrm{A} \beta$ peptides which had considerable isoforms $(2 \mathrm{Yt} 1,2 \mathrm{KJ} 7)$ or for the bacterial neprilysin. The affinity and efficacy of human neprilysin was specifically evaluated against the human $A \beta$ verities (Table 2 ). The two recombinant human neprilysin assessed in this study were produced from different expression systems. Despite considerably homology between 5JMY and 6GID, the affinity (Km values) and efficacy (Specific Activity) of enzyme kinetics against different human $\mathrm{A} \beta$ peptides varied greatly (Table 2). 6GID-4XFO and 5JMY-4XFO enzyme kinetics showed the least Specific Activity and $\mathrm{Km}$ values respectively (Table 2). While the 6GID-5TPT and 6GID-4XFO enzyme kinetics showed the highest Specific Activity and $\mathrm{Km}$ values respectively (Table 2).

\section{DISCUSSION}

This study reports a novel approach to evaluating enzyme-substrate kinetics based on the kinetics of a known prototype and estimating the kinetics of the novel enzyme-substrate types using the number of molecular interactions observed between the enzyme and substrate. Such a molecular modelling approach to predicting the enzymesubstrate kinetics can be valuable in the optimization of correct recom-

\begin{tabular}{|c|c|c|c|c|}
\hline & 5JMY & 6GID & 4XBH & $6 \mathrm{GHX}$ \\
\hline $\mathrm{A} \beta_{1-40}$ & 48 & 6 & 115 & 1 \\
\hline 4XFO & 8 & 1 & 10 & 1 \\
\hline $5 \mathrm{TPT}$ & 620 & 77 & 498 & 145 \\
\hline 3SGP & 213 & 6 & 100 & 32 \\
\hline $2 \mathrm{ROZ}$ & 2370 & 1487 & 4398 & 908 \\
\hline 2YT1 & 2312 & 973 & 11974 & 1285 \\
\hline 4YN0 & 1235 & 2 & 970 & 1370 \\
\hline $2 \mathrm{KJ} 7$ & 344 & 67 & 887 & 242 \\
\hline $1 \mathrm{NMJ}$ & 34 & 15 & 92 & 31 \\
\hline $4 \mathrm{DBB}$ & 24 & 34 & 1100 & 357 \\
\hline $2 \mathrm{BFI}$ & 2 & 1 & 34 & 2 \\
\hline $2 \mathrm{ONX}$ & 7 & 2 & 30 & 1 \\
\hline
\end{tabular}




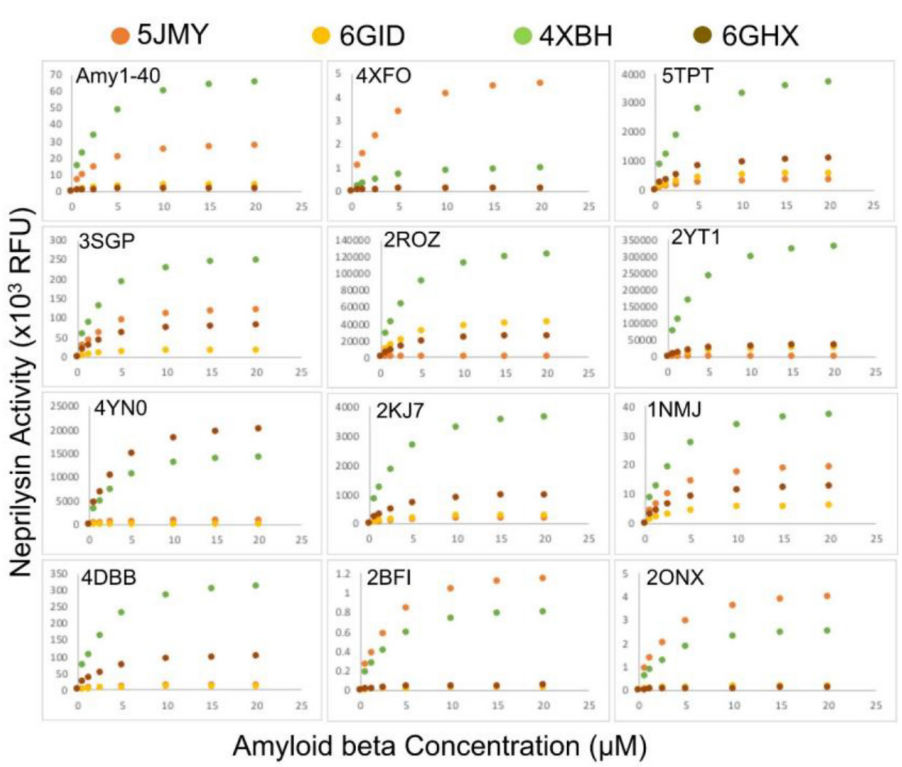

Figure 1: Enzyme-substrate kinetic curve of various neprilysin (5JMY, 6GID, $4 \mathrm{XBH}$ and $6 \mathrm{GHX}$ ) and Amyloid $\beta$ peptides (4XFO, 5TPT, 3SGP, 2ROZ, 2YT1, $\left.4 \mathrm{YNO}, 2 \mathrm{KJ} 7,1 \mathrm{NMJ}, 4 \mathrm{DBB}, 2 \mathrm{BFI}, 2 \mathrm{NX}, \mathrm{A} \beta_{1-40}\right)$ under fixed neprilysin $(5 \mathrm{nM})$ concentration.

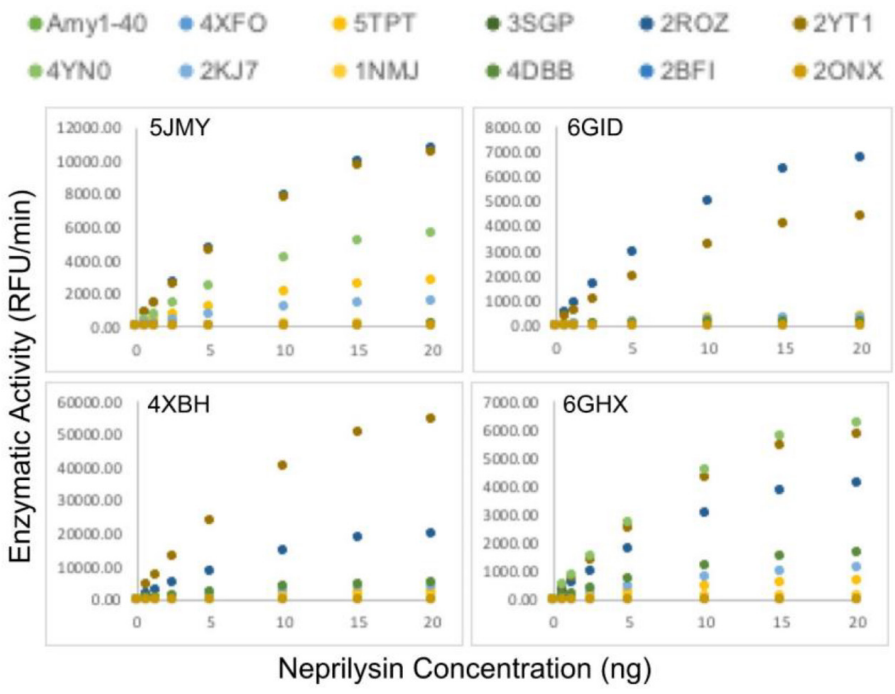

Figure 2: Enzyme-substrate kinetic curve of various neprilysin (5JMY, 6GID, $4 \mathrm{XBH}$ and $6 \mathrm{GHX}$ ) and Amyloid $\beta$ peptides (4XFO, 5TPT, 3SGP, 2ROZ, 2YT1, 4YN0, 2KJ7, 1NMJ, 4DBB, 2BFI, 2ONX, $\left.A \beta_{1-40}\right)$ under fixed substrate $(15 \mu \mathrm{M})$ concentration.

binant enzyme candidates for therapeutic development. This study also demonstrates the merit of the molecular modelling approach in predicting the enzyme-substrate kinetics using the neprilysin-Amyloid $\beta(A \beta)$ peptides as a prototype. The neprilysin-Amyloid $\beta(A \beta)$ was selected as the enzyme-substrate prototype as recent studies have indicate the potential role of developing recombinant neprilysin as a therapeutic candidate for treating Alzheimer's disease (AD)., ${ }^{2,6,8,9,16}$

Therapeutic development of neprilysin for use in treating $\mathrm{AD}$ will require establishing the optimal enzyme kinetics against $\mathrm{AD}$ specific $\mathrm{A} \beta$ peptides. ${ }^{2,8,9}$ Although the association $A \beta$ peptides in the progression of $\mathrm{AD}$ is well established, developing effective treatment will require

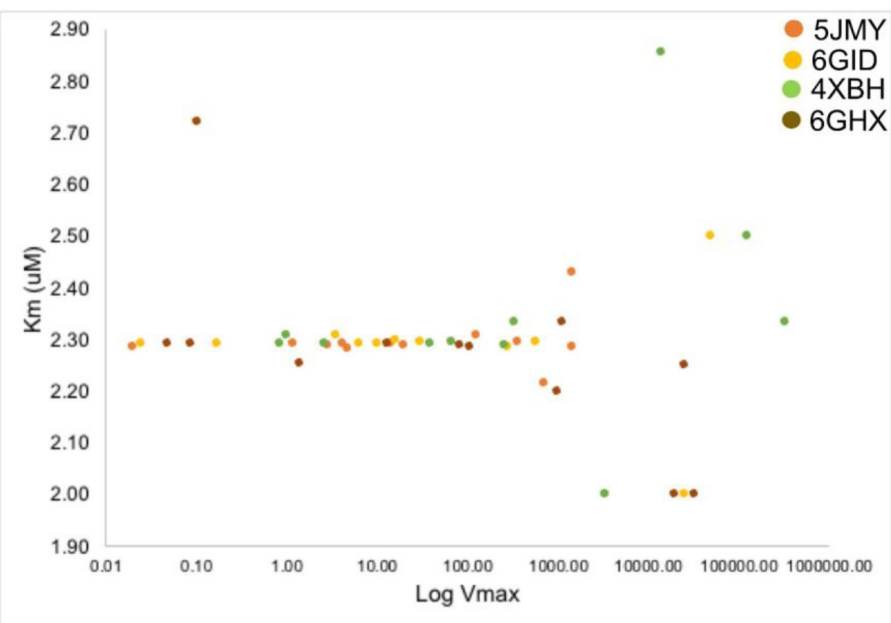

Figure 3: An XY plot of Km and Log Vmax values of various neprilysin (5JMY, 6GID, 4XBH and 6GHX) and Amyloid $\beta$ peptide (4XFO, 5TPT, 3SGP, 2ROZ, 2YT1, $\left.4 \mathrm{YNO}, 2 \mathrm{KJ} 7,1 \mathrm{NMJ}, 4 \mathrm{DBB}, 2 \mathrm{BFI}, 2 \mathrm{ONX}, \mathrm{A} \beta_{1-40}\right)$ combination kinetics.

Table 2: Neprilysin (5JMY, 6GID) activity against different human amyloid peptides (A $\left.\beta_{1-40}, 4 X F 0,5 T P T, 3 S G P\right)$.

\begin{tabular}{lcccc} 
& \multicolumn{2}{c}{ 5JMY } & \multicolumn{2}{c}{ 6GID } \\
& $\begin{array}{c}\text { Specific Activity } \\
(\mathrm{nmols} / \mathrm{min} / \mu \mathrm{g})\end{array}$ & $\mathrm{Km}(\mu \mathrm{M})$ & $\begin{array}{c}\text { Specific Activity } \\
\text { (nmols/min/ } \mu \mathrm{g})\end{array}$ & $\mathrm{Km}(\mu \mathrm{M})$ \\
$\mathbf{A} \beta_{1-40}$ & $20.63 \pm 1.71$ & $2.29 \pm 0.04$ & $25.88 \pm 1.65$ & $2.31 \pm 0.02$ \\
4XFO & $34.33 \pm 1.93$ & $2.28 \pm 0.02$ & $0.75 \pm 0.01$ & $2.72 \pm 0.05$ \\
5TPT & $2666.67 \pm 60.42$ & $2.30 \pm 0.01$ & $4235.29 \pm 102.82$ & $2.29 \pm 0.02$ \\
3SGP & $923.08 \pm 21.85$ & $2.31 \pm 0.01$ & $114.83 \pm 5.46$ & $2.30 \pm 0.01$
\end{tabular}

specific and selective cleaving of a variety of $A \beta$ peptides. ${ }^{14-17}$ Depending on the variation in the site of cleavage in the amyloid precursor protein a variety of $\mathrm{A} \beta$ peptides can be generated, which may impact the pathophysiology of $\mathrm{AD}$ differently. ${ }^{17-19}$ The variable nature of $\mathrm{A} \beta$ peptides will influence the extent to which they are further enzymatically degraded by neprilysin. As shown in this study considerable variation in the affinity and efficacy of different recombinant human neprilysin against $A \beta$ peptides was observed. Consistent with this observation a previous study has reported the significant variability in the efficiency with which neprilysin can degrade murine versus human $\mathrm{A} \beta$ peptides. ${ }^{1,3,9}$ Besides such inter-species variability in the neprilysin efficacy, this study also demonstrated prevalence of intra-species variability in humans. This intra-species variability will necessitate selection of optimal combination of different recombinant neprilysin for reducing $\mathrm{A} \beta$ peptides in $\mathrm{AD}$. The approach described in this study provides an evidence based rationalization for developing such recombinant neprilysin combinations. It is necessary that the recombinant neprilysin combinations are aligned to the nature of $\mathrm{A} \beta$ peptides in the patients with $\mathrm{AD}$ and this can be achieved through current imaging modalities with spectral analysis feature. ${ }^{10,17-19}$ Once the nature of $A \beta$ peptides is established the modelling approach described in this study can be used to identify the recombinant neprilysin which will be most effective to optimally reduce $A \beta$ peptides to achieve the desired therapeutic efficacy. For instance in this study although both human recombinant neprilysin (5JMY and 6 GID) had similar efficiency to cleave $A \beta_{1-40}$, they had variable efficiency against human $A \beta$ precursor protein and $A \beta$ peptide fragments. Hence suggesting that in the $\mathrm{AD}$ patients with higher levels of $\mathrm{A} \beta$ precursor 
protein, 6GID will have better efficacy than 5JMY. In contrast $\mathrm{AD}$ patients with higher levels of $A \beta$ peptide fragments will benefit from 5JMY compared to using 6GID. Further such an approach based on patient specific $A \beta$ peptides will be pave way for personalised medicine.

\section{CONCLUSION}

In conclusion, this study describes a novel approach of correlating the molecular modelling of enzyme-substrate interactions with enzyme kinetics of the known prototype to predict the enzyme kinetics of similar other enzyme and substrate combinations. Such an enzyme kinetics modelling approach can be helpful in the developing of recombinant enzymes/peptides for personalised therapeutic applications.

\section{ACKNOWLEDGEMENT}

Research support from University College Dublin-Seed funding/ Output Based Research Support Scheme (R19862, 2019), Royal Society-UK (IES $\backslash R 2 \backslash 181067,2018)$ and Stemcology (STGY2708, 2020) is acknowledged.

\section{CONFLICT OF INTEREST}

The author declares no conflict of interest.

\section{ABBREVIATIONS}

A $\beta$ : Amyloid- $\beta$; AD: Alzheimer's disease; PDB: Protein data bank.

\section{SUMMARY}

This study describes predictive modelling of enzyme kinetics based on the molecular interactions (Hydrogen bonds) between the enzymesubstrate and using the enzyme kinetics of a known prototype. Such a predictive modelling approach will serve as a refinement tool to personalised therapeutic applications.

\section{REFERENCES}

1. Becker M, Moore A, Naughton M, Boland B, Siems WE, Walther T. Neprilysin degrades murine Amyloid- $\beta(A \beta)$ more efficiently than human $A \beta$ : further implication for species-specific amyloid accumulation. Neurosci Lett. 2018;686:74-9. doi: 10.1016/j.neulet.2018.08.028, PMID 30144539

2. Nalivaeva NN, Zhuravin IA, Turner AJ. Neprilysin expression and functions in development, ageing and disease. Mech Ageing Dev. 2020;192:111363. doi: 10.1016/j.mad.2020.111363.

3. Gregoriou GC, Patel SD, Winters BL, Bagley EE. Neprilysin controls the synaptic activity of neuropeptides in the intercalated cells of the amygdala. Mol Pharmacol. 2020;98(4):454-61. doi: 10.1124/mol.119.119370, PMID 32606204.

4. Götz J, Bodea LG, Goedert M. Rodent models for Alzheimer disease. Nat Rev Neurosci. 2018;19(10):583-98. doi: 10.1038/s41583-018-0054-8, PMID 30194347
5. Graykowski D, Kasparian K, Caniglia J, Gritsaeva Y, Cudaback E. Neuroinflammation drives APOE genotype-dependent differential expression of neprilysin. $J$ Neuroimmunol. 2020;346:577315. doi: 10.1016/j.jneuroim.2020.577315.

6. Feinkohl I, Schipke CG, Kruppa J, Menne F, Winterer G, Pischon T, Peters O. Plasma amyloid concentration in Alzheimer's disease: performance of a highthroughput amyloid assay in distinguishing Alzheimer's disease cases from controls. J Alzheimers Dis. 2020;74(4):1285-94. doi: 10.3233/JAD-200046, PMID 32176645.

7. Maitre M, Klein C, Patte-Mensah C, Mensah-Nyagan AG. Tryptophan metabolites modify brain Abeta peptide degradation: A role in Alzheimer's disease? Prog Neurobiol. 2020;190:101800. doi: 10.1016/j.pneurobio.2020.101800.

8. Rofo F, Ugur Yilmaz C, Metzendorf N, Gustavsson T, Beretta C, Erlandsson A, Sehlin D, Syvänen S, Nilsson P, Hultqvist G. Enhanced neprilysin-mediated degradation of hippocampal $A \beta 42$ with a somatostatin peptide that enters the brain. Theranostics. 2021;11(2):789-804. doi: 10.7150/thno.50263, PMID 33391505.

9. Campos CR, Kemble AM, Niewoehner J, Freskgård PO, Urich E. Brain Shuttle neprilysin reduces central Amyloid-betalevels. PLOSONE. 2020;15(3):e0229850. doi: 10.1371/journal.pone.0229850, PMID 32155191.

10. Vasilev DS, Dubrovskaya NM, Zhuravin IA, Nalivaeva NN. Developmental profile of brain neprilysin expression correlates with olfactory behaviour of rats. J Mo Neurosci. 2021. doi: 10.1007/s12031-020-01786-3, PMID 33433852.

11. Kumar AHS. Molecular Docking of Natural compounds from Tulsi (Ocimum sanctum) and neem (Azadirachta indica) against SARS-CoV-2 Protein Targets. BEMS Reports. 2020;6(1):11-3. doi: 10.5530/bems.6.1.4

12. Sankhe R, Rathi E, Manandhar S, Kumar A, Pai SRK, Kini SG, Kishore A Repurposing of existing FDA approved drugs for neprilysin inhibition: an in-silico study. J Mol Struct. 2021;1224:129073. doi: 10.1016/j.molstruc.2020.129073.

13. Yang Z, Lasker K, Schneidman-Duhovny D, Webb B, Huang CC, Pettersen EF GoddardTD, Meng EC, Sali A, Ferrin TE. UCSF Chimera, MODELLER, and IMP: an integrated modeling system. J Struct Biol. 2012;179(3):269-78. doi: 10.1016/j. jsb.2011.09.006, PMID 21963794.

14. Nakamura A, Kaneko N, Villemagne VL, Kato T, Doecke J, Doré V, Fowler C Li QX, Martins R, Rowe C, Tomita T, Matsuzaki K, Ishii K, Ishii K, Arahata Y, Iwamoto S, Ito K, Tanaka K, Masters CL, Yanagisawa K. High performance plasma amyloid-beta biomarkers for Alzheimer's disease. Nature. 2018;554(7691):249-54. doi: 10.1038/nature25456, PMID 29420472

15. Shigemoto Y, Sone D, Maikusa N, Okamura N, Furumoto S, Kudo Y, Ogawa M, Takano H, YokoiY, Sakata M, TsukamotoT, Kato K, Sato N, Matsuda H. Association of deposition of tau and amyloid-beta proteins with structural connectivity changes in cognitively normal older adults and Alzheimer's disease spectrum patients. Brain Behav. 2018;8(12):e01145. doi: 10.1002/brb3.1145, PMID 30358161.

16. Yamamoto $N$, Nakazawa $M$, Nunono $N$, et al. Protein kinases $A$ and $C$ regulate amyloid-beta degradation by modulating protein levels of neprilysin and insulindegrading enzyme in astrocytes. Neurosci Res. 2020.

17. Saa PA, Nielsen LK. Formulation, construction and analysis of kinetic models of metabolism: a review of modelling frameworks. Biotechnol Adv. 2017;35(8):981-1003. doi: 10.1016/j.biotechadv.2017.09.005, PMID 28916392.

18. Moss S, Subramanian V, Acharya KR. Crystal structure of peptide-bound neprilysin reveals key binding interactions. FEBS Lett. 2020;594(2):327-36. doi: 10.1002/1873-3468.13602, PMID 31514225.

19. Summers KL, Schilling KM, Roseman G, Markham KA, Dolgova NV, Kroll T, Sokaras D, Millhauser GL, Pickering IJ, George GN. X-ray Absorption Spectroscopy Investigations of copper(II) Coordination in the Human amyloid beta Peptide. Inorg Chem. 2019;58(9):6294-311. doi: 10.1021/acs.inorgchem.9b00507، PMID 31013069. 